\title{
The Cure from Nature: The Extraordinary Anticancer Properties of Ascorbate (Vitamin C)
}

Domenico Mastrangelo ${ }^{1^{*}}$, Lauretta Massai ${ }^{1}$, Giuseppe Fioritoni ${ }^{2}$, Francesco Lo Coco ${ }^{3}$ and Ranuccio Nuti ${ }^{1}$

${ }^{1}$ Departiment of Medical, Surgical and Neurological Sciences - University of Siena, Italy

${ }^{2}$ Pescara Cell Factory Foundation - Pescara, Italy

${ }^{3}$ Department of Biomedicine and Prevention, University of Rome TorVergata, Via Montpellier 1, 00133 Rome, Italy

*Corresponding author: Domenico Mastrangelo, MD, Departiment of Medical, Surgical and Neurological Sciences, University of Siena, Italy, Tel: 00390577234044; Email: mastrangelod10@gmail.com

Rec date: Feb 03, 2016; Acc date: Feb 08, 2016; Pub date: Feb 10, 2016

Copyright: (c) 2016 Mastrangelo D, et al. This is an open-access article distributed under the terms of the Creative Commons Attribution License, which permits unrestricted use, distribution, and reproduction in any medium, provided the original author and source are credited.

\begin{abstract}
The anticancer properties of Vitamin C (ascorbic acid o sodium ascorbate) are known since at least four decades, However, being a cheap and "natural" product, Vitamin $\mathrm{C}$ is not patentable and therefore has never been developed as an anticancer molecule.
\end{abstract}

Recent in vitro investigations have confirmed the extraordinary antitumor properties of high doses of Vitamin $\mathrm{C}$ (sodium ascorbate), particularly when administered by the intravenous route, and phase I/II randomized, controlled clinical trials have been started to verify its anticancer properties in vivo.

Unfortunately, the controlled clinical trials performed so far, do not confirm the extraordinary results obtained with Vitamin C (sodium ascorbate) in vitro. However, this may depend on a number of different factors, such as the pharmaceutical preparation (Sodium ascorbate may be more suitable than buffered ascorbic acid), the schedule of administration (slow infusion better than rapid infusion), tumor tissue oxygenation (Cancer tissue oxygenation is lower that oxygenation of tumor cell lines, in vitro), etc., which deserve further in depth investigation.

Even with these limitations, Vitamin C (sodium ascorbate) in high doses, administered by intravenous route, beyond being extremely effective in vitro, against a number of human tumor cell lines, is safe, has minimal contraindications, improves the quality of life of patients, and is highly selective for cancer cells.

The Authors discuss these important aspects and suggest possible solutions to improve the in vivo anticancer effects of Vitamin C (sodium ascorbate).

Keywords: Vitamin C; Ascorbic acid; Sodium ascorbate; Cancer; Free radicals; Oxidative stress; Antioxidants; Redox molecules

\section{Introduction}

Ascorbate (Vitamin C) is ubiquitous. It is found throughout the plant and animal kingdoms, where its roles are often not known or are poorly understood [1].

Among its multiple physiological functions, ascorbate:

1. Helps in the metabolism of tyrosine, folic acid and tryptophan;

2. Increases the elimination of cholesterol;

3. Contributes to the synthesis of catecholamines;

4. Helps the body to absorb and breakdown histamine;

5. Enhances the absorption of non-heme iron;

6. Is essential for the synthesis of collagen (its most widely known physiological function);

7. As an antioxidant, it neutralizes free radicals (it is a reducing agent and a "scavenger" of free radicals);

8. Protects DNA from damage due to free radicals and mutagens;

9. Reduces the risk of premature death;
10. Fights off widespread environmental pollutants;

11. Prevents the development of nitrosamines [2]

Though ubiquitous, ascorbate is not produced by humans, guinea pigs, some primates, a particular type of fruit eating bat, the majority of fishes and birds [3], who depend on diet for the assumption and use of this fundamental nutrient.

The anticancer properties of ascorbate are known since at least four decades, but the interest for ascorbate as an anticancer "drug" has recently revived, due to in vitro investigations showing that ascorbate in high concentrations is highly toxic for a wide variety of human tumour cell lines, while it is almost completely harmless for their normal counterpart. However, the most recent clinical trials on ascorbate in high concentration, administered by the intravenous route, do not seem to confirm the in vitro efficacy. This is most probably due to several different problems concerning the pharmaceutical form, the administration schedule, and a number of other problems, which are discussed in this review. 


\section{How Much Vitamin C?}

Most animals can synthesize their own requirements of Vitamin C but since humans cannot, they are totally dependent upon dietary intake of this vitamin [4]. In fact, the vast majority of animals produce their own requirement of Vitamin C, whose synthesis is greatly enhanced during stress [5].

For example, control rats metabolize, each day, $1.8 \mathrm{mg}$ of Vitamin C per $100 \mathrm{mg}$ body weight, while pentobarbital, 3-methylcholanthrene, and chloretone-treated rats, produce about $10 \mathrm{mg} / 100 \mathrm{mg}$ of body weight [6].

A $70 \mathrm{~kg}$ goat (the average weight used in calculations for adult males) will produce Vitamin C at $33 \mathrm{mg} / \mathrm{kg} /$ day or $2.31 \mathrm{~g} /$ day. Under stress or disease, the goat can produce $190 \mathrm{mg} / \mathrm{kg} / \mathrm{day}$ or $13.3 \mathrm{~g}$ of vitamin $\mathrm{C}$ a day $[7,8]$. By extension, man, who does not produce Vitamin C, should be supplemented with grams of the vitamin, although the US and European dietary references, recommend daily amounts in the order of milligrams [9-11].

This is a clear indication that RDAs are designed to prevent deficiency disease, with a little nutrients to spare, but do not guarantee an optimal health condition.

Given all the above, and the fact that "vitamin" is, by definition, "any of various organic substances that are essential in minute quantities" [12].

Vitamin C cannot properly be defined a "vitamin", and the term "ascorbate" should be preferred to define this simple substance, with pleiotropic functions and benefits for human health and well-being.

\section{Hypoascorbemia and Chronic Subclinical Scurvy: The Source of Every Disease}

According to Irwin Stone, a biochemist who studied in depth the many functions and roles of ascorbate in man, a balanced diet alone, can only effectively prevent scurvy, but cannot guarantee a good health condition. On this ground, he coined the term "hypoascorbemia" to define the inability of humans and a few other species, to synthesize ascorbic acid because of the lack of the enzyme L-gulonolactone oxidase (GLO) [13] as a consequence of an "inborn error of carbohydrate metabolism" [14-16].

This defect, now very well-known and characterized [17], led Stone, and other scientists, such as Linus Pauling $[18,19]$ to hypothesize that to be in good health man needs mega-doses (several grams a day), rather than doses in the order of milligrams, as stated by the Recommended Daily Allowances (RDAs) [20].

Interestingly enough, Stone also hypothesized that almost every known disease (including cancer, degenerative and chronic diseases, cardiovascular diseases, etc.) largely depend on inadequate intake of ascorbate through food, and a consequent "hypoascorbemia", leading to the clinical condition he defined "Chronic Subclinical Scurvy" (CSS) [21,22].

In 1982, in a letter addressed to the Nobel laureate Albert SzentGyorgyi, Irwin Stone, wrote: "Because of the poor and inadequate full correction of the human defective gene for GLO (too little daily ascorbate intake), every cancer victim was born scorbutic, after a 9month intrauterine bout with scurvy. This poor correction, due to grossly inadequate maternal daily intakes of ascorbate, continues throughout the lifetime of the victims, exposing them constantly to the deleterious physiological insults of Chronic Subclinical Scurvy (the CSS Syndrome)..." [23].

\section{Mega-Doses of Vitamin C and Cancer}

The letter thus continued: “... This (Chronic Subclinical Scurvy) is a large factor in the genesis of the cancer. Every cancer victim being treated by orthodox oncologists suffers also from a bad case of the CSS Syndrome. When the orthodox cut, burn, and poison techniques prove too much, the cancer victims do not die solely from the cancer lesion, but are pushed into their grave by the exacerbated uncorrected scurvy that is always present. We and other workers in this field haven't really realized the enormous size of daily dosage of ascorbate required for therapy and survival in cancer?' [23,24]. that:

Therefore, in 1982, it was already clear, at least to some scientists,

1. Cancer (as well as many other chronic diseases) depends on an insufficient intake of ascorbate and the consequent hypoascorbemia, leading to CSS

2. Cancer development can be effectively treated by ascorbate

3. The doses of ascorbate to be used, in the treatment of cancer, must be in the order of several grams per day, i.e. from 300 to several thousand times the amount suggested by the RDAs

As a matter of fact, in 1974, Irwin Stone had already reported about the treatment of leukemia with mega-doses of ascorbate [18].

In the same year, Cameron and Campbell published the results of a clinical trial, showing that, in "untreatable" cancer patients, ascorbate in high doses can bring about some significant improvement in morbidity and mortality [25].

Two years later, Cameron and Pauling showed that the survival of untreatable cancer patients increased by a factor of about 3 in the majority of cases, and about 20 in $10 \%$ of them, under treatment with 10 grams of ascorbate per day, starting with the intravenous route, followed by oral administration [26].

Later on, the same authors confirmed, in another article, that 10 or more grams of ascorbate per day, significantly prolong the survival and improve the quality of life of untreatable cancer patients [27].

The Mayo Clinic responded to the mentioned articles, with two studies, but the first one, in spite of the recommendations of Cameron and Pauling, included patients previously treated with radio-/ chemotherapy [28], and the authors themselves, regarding this first study, wrote: "He [Linus Pauling] speculated that our study did not replicate the strongly positive results reported, because the cytotoxic drugs destroy the body's protective mechanisms, and Vitamin $C$ probably functions largely by potentiating these mechanisms. Although the scientific basis of this conclusion seemed to us obscure (!), we could not disprove Dr. Pauling's contention with the evidence produced by our study".

Regarding the second study, published in 1985 [29], while the Author's intention was to follow the standard methodology of the randomized, double blind, placebo-controlled clinical trial, in the "Method" section of the article, the Authors write: "The nature and purpose of the study were fully discussed with each patient, with specific emphasis on the fact that they would receive either Vitamin $C$ or an inert placebo ..."; in other words, this study was not "double blind", as patients were fully aware of treatments used! The Authors refused to send the raw data to Pauling and other Authors who 
requested them, but it seems reasonable to assume that informing cancer patients that they could undergo a placebo treatment, is both ethically questionable, and methodologically inappropriate!

Although so seriously flawed, both studies were accepted by the scientific community as the proof of the inefficacy of Vitamin C in fighting cancer.

\section{In vitro Evidence of the Effectiveness of Ascorbate in the Treatment of Cancer}

In 2005, the proof that the accepted views of the inefficacy of high doses of ascorbate to treat cancer was wrong, came from Chen and Coll. who demonstrated that pharmacologic ascorbic acid concentrations, selectively kill cancer cells by acting as a pro-drug to deliver hydrogen peroxide $\left(\mathrm{H}_{2} \mathrm{O}_{2}\right)$ to cancerous tissues [30,31], and a number of different investigators, worldwide, demonstrated the in vitro efficacy of ascorbate in inducing apoptotic/necrotic cell death of a multitude of human tumor cell lines. A good summary of these investigations is reported by Park [32].

We have investigated, ourselves, the effects of high concentrations of ascorbate on retinoblastoma (Y79) [33], uveal melanoma (OCM1, C918) [34], human promyelocytic leukemia (HL60) [35], and a number of other human myeloid leukemia cell lines [36], and almost invariably found that two hours of exposure to millimolar (mM) concentrations of ascorbate, determines apoptotic/necrotic cell death of up to $90 \%$ of the cells in culture, at concentrations ranging from 3 to $5 \mathrm{mM}$.

Interestingly enough, our results, contrary to what is currently believed, demonstrate that ascorbate gets into cancer cells almost immediately, after exposure, and exerts its cytotoxic effects within the cell and not outside of it.

\section{Anticancer Mechanisms of High Doses of Ascorbate}

As previously mentioned, the work of Chen et al. [30,31] has largely demonstrated that ascorbate in high concentrations is a pro-drug of $\mathrm{H}_{2} \mathrm{O}_{2}$, even though the cytotoxic effects of the oxidation products of ascorbate, was already known more than four decades ago [37-39].

Although it is known that $\mathrm{H}_{2} \mathrm{O}_{2}$ can have both positive (signaling) and negative (damage) effects, depending on the amount, increased levels of hydrogen peroxide within the cells, such as those produced by the intravenous administration of high doses of ascorbate, can result in oxidative stress and cause cellular damage [40].

However, the role of ascorbate as a pro-drug of $\mathrm{H}_{2} \mathrm{O}_{2}$, when administered in high doses, has been questioned by different authors [41-43], and other mechanisms have been advocated to explain the anticancer properties of this nutrient. Among others:

1. Vitamin C oxidation products such as dehydroascorbic acid, 2,3 diketogulonic acid, and 5-methyl 1-3,4-dehydroxytetrone, all degradation products of ascorbic acid, have demonstrated antitumor activity [44-48]. The antitumor activity shown by these compounds could be due to their ability to produce active molecular species that inhibit tumor growth such as $\mathrm{H}_{2} \mathrm{O}_{2}$ and certain aldehydes.

2. Large amounts of Vitamin $\mathrm{C}$ may lead to depletion of aminoacids essential for tumor growth [49].

3. Dehydroascorbic acid (the oxidized, non-ionic and more lipid soluble form of ascorbate) may promote lipid peroxidation, and secondary products of lipid peroxidation may, in turn, have an inhibitory action on human malignant cell proliferation [50-53].

4. Dehydroascorbic acid itself may work as a mitotic inhibitor [54].

5. When provided in large quantities ascorbate enhances the removal of sodium via the urine thereby reducing the level of sodium ions in the serum. In fact, cancer usually shows a disturbed sodium/ potassium ratio [37].

6. Since it is known that in the process of prostaglandin biosynthesis, the release of arachidonic acid from cell membrane phospholipids is implicated as one of the synergistic signals leading to cell proliferation, another possible role of ascorbate, in fighting cancer, consists in the inhibition of prostaglandins of the two series in carcinoma cells $[55,56]$.

Ascorbate also controls tumor growth by at least two other important, even if indirect, mechanisms: by promoting the collagen synthesis, it reinforces the natural barrier against cancer infiltration and metastatic spread $[57,58]$ and by ensuring the correct working of the immune system, it inhibit tumor growth and spread by enhancing the natural defense mechanisms of immune surveillance against cancer [59-61].

\section{High Doses of Ascorbate in Cancer: Vain Promise or Unaccaptable Truth?}

The anticancer effects of ascorbate are known since at least 1952 [62], but, after the two Mayo clinic studies mentioned above [28,29], the medical establishment has dismissed ascorbate as ineffective against cancer.

However, as we have seen in the previous sections, both the Mayo Clinic studies were seriously flawed: the first one [28] by admission of the Authors themselves, and the second one [29], not only because it violated the requirements for a double blind clinical trial, but also because:

- it used relatively low oral doses for short periods, rather than the lifetime combination of high oral and intravenous (IV) doses, as in the Cameron and Pauling study;

- it discontinued therapy as soon as the patient worsened;

- it enrolled only patients affected by colorectal cancer [63-65].

To add evidence to the work done by Cameron and Pauling, Japanese researchers also found increased survival times similar, in patients treated with Ascorbate [66,67], and Pauling himself reassessed the survival rates of cancer patients treated with ascorbate, in 1990 [68], and 1993 [69], confirming the results of the former investigations, even though both these papers have been largely ignored by the scientific community.

Cameron and Campbell also tried to publish another article where they demonstrated that the survival rate of terminal cancer patients treated with ascorbate, is significantly higher than that of the controls, but they couldn't disseminate this knowledge as they would have [70].

Subsequently, Jackson and coll. reported their sixteen yearsexperience with high doses of intravenous ascorbate in cancer and other diseases, confirming that this treatment is safe and effective, for cancer patients [71]. 


\section{Improving Ascorbate Treatment of Cancer}

Current clinical evidence for a therapeutic effect of high-dose of intravenous (IV) vitamin C has been defined "ambiguous", and, despite the forty years of research since the initial reports on high-dose of IV ascorbate, its utility in fighting cancer remains controversial, at least, to some authors

To our opinion, this is a partial and biased view of the reality. While many questions remain, concerning the efficacy of high doses of ascorbate in vivo, including the optimal dose, timing, pharmaceutical preparation, and combination with other antioxidants, a few firm points remain, which represent a clear indication to the use of this nutrient, in high IV concentration, to treat cancer; among others:

- It improves the quality of life of cancer patients [72]

- It prolongs their survival $[26,27,73]$

- It potentiates the cytotoxic effects and reduces the side effects of conventional chemotherapy [74]

- It is remarkably safe in both physiologic, and pharmacologic concentrations [75]

- It boosts the immune response, in cancer patients [76-79]

- It increases the host resistance to neoplasia $[80,81]$

- It protects against the development of neoplasia $[82,83$ ]

- It is an epigenetic modulator of genes with a key role in cancer development $[84,85]$

- It is highly cytotoxic in vitro against a number of different human tumor cell lines [30,31,33-36]

- It exert a powerful cytotoxic effect against colorectal cancer cells refractory to targeted therapies $[86,87]$.

The advantages of the use of high doses of intravenous ascorbate to treat cancer, however, should not lead to overlook the many problems that still remain to be solved, before translating the extraordinary in vitro data into a clinical reality.

\section{Conclusion}

In the era of the "Evidence Based Medicine", ascorbate is still considered, by some Authors, ineffective in preventing and treating cancer even though prominent scientists have demonstrated its effectiveness in studies published on prestigious journals with high Impact Factor (IF) [26,27].

Ironically, the "evidence" that has definitively dismissed ascorbate as an anticancer molecule, is limited to the two articles published by the Mayo Clinic oncologists which, as we have previously shown $[29,30]$, were both severely flawed even though published on a highly esteemed journal

In very many ways, this is not surprising. Ascorbate is a cheap and "natural" nutrient that, as such, cannot undergo any patent submission, and no pharmaceutical company would ever invest on it to prevent or cure cancer. This is, according to our opinion, the only reason why ascorbate is still waiting for a definitive allocation within the therapeutic tool bag of anticancer "drugs", even though its effectiveness is very well known since at least more than half a century.

The anticancer effects of ascorbate in vivo, most probably depend on a number of variables which deserve further investigation; among others:
- The pharmaceutical preparation (ascorbic acid may be more difficult to handle than sodium ascorbate) [88]

- The time and schedule of administration (slow infusion to be preferred) [89-91]

- The level of tissue oxygenation (cell cultures are better oxygenated than tumor tissues, and this may explain the differences in the outcomes of treatment of cancer cells in vitro, as compared to in vivo studies) [92]

- The level of blood glucose (glucose may interfere with the uptake of ascorbate by cancer cells $[93,94]$.

All the above factors need to be further investigated, to optimize the treatment of cancer with high doses of IV ascorbate, but even with these limitations in mind, ascorbate is and remains the most powerful and promising anticancer agent, since it is:

- "natural";

- inexpensive;

- safe;

- non-toxic for the body, even in high concentrations;

- highly toxic (and selective!) for cancer cells;

- completely harmless for their normal counterpart.

Is there anything new under the sun?

Ascorbate as an anticancer agent, has been around for at least four decades, thanks to the passionate efforts of pioneers such as Albert Szent-Gyorgyi, Frederik Klenner, Irwin Stone, Linus Pauling, Ewan Cameron, and a few others; but the medical establishment could hardly, and still cannot accept the idea that such a simple molecule, a "nutrient", could be so powerful in fighting cancer.

During these four decades, prominent scientists such as Linus Pauling, have been often ridiculed by the medical establishment, for their ideas and opinions regarding the role of Vitamin $\mathrm{C}$ in the treatment of several diseases, including cancer, but, “.. three things cannot be hidden for a long time: the sun, the moon, and the truth!".

In December 2015 [85], researchers have finally discovered that ascorbate efficiently kills colon cancer cell, resistant to conventional treatments; ironically, this demonstration pertains a cancer which Creagan et al., at Mayo Clinic, found insensitive to ascorbate [30]!. An epochal event is taking place in cancer treatment, but the misunderstanding is always in ambush! The Authors of a related article [84] conclude: “... Pauling may have been correct on the use of high doses of Vitamin $C$ for cancer therapy, but for wrong reasons - not as an antioxidant, but as a pro oxidant anticancer agent'; knowing the real story of Vitamin C, one can easily realize that this is simply not true! Pauling never considered the anti- or pro- oxidant properties of ascorbate; he rather pointed out its effects as a booster of the immune response! The distinction itself, between anti- or pro- oxidant properties of ascorbate, as related to the dose, may be misleading, since ascorbate seems to behave differently not just according to its dose, but rather according to the target cell, being an antioxidant for normal cells, and pro- oxidant for cancer cells.

Almost a hundred years ago, Paul Erlich, the founder of modern chemotherapy, who received the Nobel Prize for Physiology and Medicine, hypothesized the creation of the "magic bullet" for use in the fight against human disease, thus inspiring generations of scientists to devise new powerful anticancer agents: today we know that the "magic bullet" is here; ascorbate, in vitro is extremely effective and selective, as we have demonstrated in leukemic cells lines and their normal 
counterpart [36] ... to the clinical oncologists the endeavor and responsibility to translate these wonderful data in a clinical (revolutionary) reality!.

\section{References}

1. Davies MB, Austin J, Partridge DA (1991) Its chemistry and biochemistry. Royal Society of Chemistry Paperbacks Distribution Centre - Blackhorse Road-Letchworth-Herts. SG6 1HN The Royal Society of Chemistry, Cambridge.

2. Iqbal K, Khan A, Ali Khan Khattak MM (2004) Biological Significance of Ascorbic Acid (Vitamin C) in Human Health - A Review. Pak J Nutr 3: 5-13.

3. Drouin G, Godin JR, Pagé B (2011) The Genetics of Vitamin C Loss in Vertebrates. Curr Genomics 12: 371-378.

4. Chatterjee IB (1998) Vitamin C: biosynthesis, evolutionary significance and biological function. Proc Indian Natl Sci Acad B 64: 213-234.

5. Touster O, Hollmann S (1961) Nutritional and enzymatic studies on the mechanism of stimulation of ascorbic acid synthesis by drugs and carcinogenic hydrocarbons. Ann N Y Acad Sci 92: 318-323.

6. Conney AH, Bray GA, Evans C, Burns JJ (1961) Metabolic interactions between L-Ascorbic acid and drugs. Ann N Y Acad Sci 92: 115-127.

7. Chatterjee IB (1971) Evolution and the biosynthesis of ascorbic acid. Science 182: 1271-1272.

8. Jackson JA, Wong K, Krier C, Riordan HD (2005) Screening for Vitamin C in the Urine: Is it Clinically Significant? JOM 20: 259-261.

9. Levine M, Wang Y, Padayatty SJ, Morrow J (2001) A new recommended dietary allowance of vitamin C for healthy young women. Proc Natl Acad Sci USA 98: 9842-9846.

10. EFSA, Panel on Dietetic Products, Nutrition and Allergies (NDA) (2013) Scientific Opinion on Dietary Reference Values for vitamin C. EFSA J 11: 3418.

11. Frei B, Traber M (2001) The new US dietary reference for vitamin C and E. Redox Rep 6: 5-9.

12. http://www.merriam-webster.com/medical/vitamin

13. Stone I (1966) On the Genetic Etiology of Scurvy. Acta Gen Med et Gemell 15: 345-350.

14. Stone I (1966) Hypoascorbemia, the Genetic Disease Causing the Human Requirement for Exogenous Ascorbic Acid. Perspect Biol Med 10:133-134.

15. Stone I (1967) The genetic disease, hypoascorbemia: a fresh approach to an ancient disease and some of its medical implications. Acta Genet Med Gemellol 16: 52-62.

16. Stone I (1972) Hypoascorbemia, Our Most Widespread Disease. Bull Natl Health Fed 18: 6-9.

17. http://www.omim.org/entry/240400

18. Stone I (1974) Megascorbic Therapy of the Disease Called Leukemia. Cancer Control 2: 1-4.

19. Stone I (1977) My Daily Megascorbic Regime for Full Health and Long Life. Better Nutrition.

20. Panel on Dietary Antioxidants and Related Compounds; Subcommittee on Upper Reference Levels of Nutrients; Subcommittee on Interpretation and Uses of DRIs; Standing Committee on the Scientific Evaluation of Dietary Reference Intakes; Food and Nutrition Board; Institute of Medicine (2000) Dietary Reference Intakes for Vitamin C, Vitamin E, Selenium, and Carotenoids 529 pages ISBNs: Paperback: 978-0-309-06935-9 Hardcover: 978-0-309-06949-6.

21. Stone I (1979) Eight Decades of Scurvy. The Case History of a Misleading Dietary Hypothesis. Orthomol Psych 8: 58-62.

22. Stone I (1972) The Healing Factor. "Vitamin C" Against Disease. Grosset and Dunlap Inc., New York.

23. http://nutri.com/stone/

24. http://www.doctoryourself.com/jungeblut.html
25. Cameron E, Campbell A (1974) The orthomolecular treatment of cancer. Clinical trial of high dose ascorbic acid supplements in advanced human cancer. Chem Biol Interact 9: 285-315.

26. Cameron E, Pauling L (1976) Supplemental ascorbate in the supportive treatment of cancer: Prolongation of survival times in terminal human cancer. Proc Natl Acad Sci USA 73: 3685-3689.

27. Cameron E, Pauling L (1978) Supplemental ascorbate in the supportive treatment of cancer: Reevaluation of prolongation of survival times in terminal human cancer. Proc Natl Acad Sci USA 75: 4538-4542.

28. Creagan ET, Moertel CG, O'Fallon JR, Schutt AJ, O’Connell MJ, et al. (1979) Failure of high-dose vitamin C (ascorbic acid) therapy to benefit patients with advanced cancer. A controlled trial. N Engl J Med 301: 687-690.

29. Moertel CG, Fleming TR, Creagan ET, Rubin J, O'Connell MJ, et al. (1985) High-dose vitamin C versus placebo in the treatment of patients with advanced cancer who have had no prior chemotherapy. A randomized double-blind comparison. N Engl J Med 312: 137-141.

30. Chen Q, Espey MG, Krishna MC, Mitchell JB, Corpe CP, et al. (2005) Pharmacologic ascorbic acid concentrations selectively kill cancer cells: action as a pro-drug to deliver hydrogen peroxide to tissues. Proc Natl Acad Sci USA 102: 13604-13609.

31. Chen Q, Espey MG, Sun AY, Lee JH, Krishna MC, et al. (2007) Ascorbate in pharmacologic concentrations selectively generates ascorbate radical and hydrogen peroxide in extracellular fluid in vivo. Proc Natl Acad Sci USA 104: 8749-8754.

32. Park S (2013) The Effects of High Concentrations of Vitamin C on Cancer Cells Nutrients. Nutrients 5: 3496-3505.

33. Mastrangelo D, Massai L, Micheli L, Muscettola M, Cevenini G, et al. (2013) High Doses of Ascorbate Kill Y79 Retinoblastoma Cells In vitro. J Clin Exp Ophthalmol 4: 1.

34. Mastrangelo D, Massai M, Valyi-Nagy K, Muscettola M, Aglianò M, et al. (2013) Megadoses of Ascorbate as a New Chemotherapeutic Approach in Uveal Melanoma: A Preliminary In vitro Investigation. J Clin Exp Ophthalmol 4: 6.

35. Mastrangelo D, Massai L, Fioritoni G, Iacone A, Di Bartolomeo P, et al. (2013) Megadoses of Sodium Ascorbate Efficiently Kill HL60 Cells in vitro: Comparison with Arsenic Trioxide. J Cancer Ther 4: 1366-1372.

36. Mastrangelo D, Massai L, Lo Coco F, Noguera NI, Borgia L, et al. (2015) Cytotoxic effects of high concentrations of sodium ascorbate on human myeloid cell lines. Ann Hematol 94: 1807-1816.

37. Gonzalez MJ, Miranda-Massari JR (2014) New Insights on Vitamin C and Cancer. Springer Briefs in Cancer Research. ISBN 978-1-4939-1889-8.

38. Nakamura Y, Yamafuji K (1968) Antitumor activities of oxidized products of ascorbic acid. Sci Bull Fac Kyushu Univ 23: 119-125.

39. Omura H, Tomita Y, Yasuhiko N (1974) Antitumor potentiality of some ascorbate derivaties. J Fac Agr Kyushu Univ 18: 181-189.

40. Veal EA, Day AM, Morgan BA (2007) Hydrogen Peroxide Sensing and Signaling. Mol Cell 13: 1-14.

41. Carr A, Frei B (1999) Does vitamin C act as a pro-oxidant under physiological conditions? The FASEB J 13: 1007-1024.

42. Halliwell B (1999) Vitamin C: poison, prophylactic or panacea? Trends Biochem Sci 24: 255-259.

43. Hacisevki A (2009) An overview of ascorbic acid biochemistry. J Fac Pharm Ankara 38: 233-255.

44. Leung PY, Miyashita K, Young M, Tsao CS (1993) Cytotoxic effect of ascorbate and its derivative on cultured malignant and non-malignant cell lines. Anticancer Res 13: 47-80.

45. Tsao CS, Dunhan WB, Leung PY (1998) In vivo antineoplastic activity of ascorbic acid for human mammary tumor. In vivo 2: 147-150.

46. Tsao CS, Dunhan WB, Leung PY (1989) Effect of ascorbic acid and its derivatives on the growth of human mammary tumor xenografts in mice. Cancer J 5: 53-59.

47. Poydock ME (1982) Effect of combined ascorbic acid and B12 on survival of mice implanted with Erlich carcinoma and L1210 leukemia. Am J Clin Nutr 54: 1261s-1265s. 
48. Edgar JA (1970) Dehydroascorbic acid and cell division. Nature 227: 24-26.

49. Tsao CS, Miyashita K (1985) Effects of large intake of ascorbic acid on the urinary excretion of amino acids and related compounds. IRCS Med Sci 13: 855-856.

50. Sakagami H, Satoh K (1977) Pro-oxidant action of two antioxidants: ascorbic acid and gallic acid. Anticancer Res 17: 221-224.

51. Gonzalez MJ, Riordan NH (1996) The paradoxical role of lipid peroxidation on carcinogenesis and tumor growth. Med Hypotheses 46: 503-504.

52. González MJ, Schemmel RA, Dugan L Jr, Gray JI, Welsch CW (1993) Dietary fish oil inhibits human breast carcinoma growth: a function of increased lipid peroxidation. Lipids 28: 827-832.

53. Sakagami H, Satoh K, Sugaya K, Iida M, Hirota N, et al. (1996) Effect of the type of serum in the medium on sodium ascorbate-induced toxicity. Anticancer Res 16: 1937-1942.

54. Grad JM, Bahlis NJ, Reis I, Oshiro MM, Dalton WS, et al. (2001) Ascorbic acid enhances arsenic trioxide-induced cytotoxicity in multiple myeloma cells. Blood 98: 805-813.

55. Beetens JR, Hermen AG (1983) Ascorbic acid and Prostaglandin formation. Int J Vitam Nutr Res 24:131s-144s.

56. El Attar TMA, Lin HS (1992) Effect of vitamin C on prostaglandin synthesis by fibroblasts and squamous carcinoma cells. Prostagl Leukot Essent Fatty Acids 47: 253-257.

57. Kennedy JF (1976) Chemical and biochemical aspects of the glycosaminoglycans and proteoglycans in health and disease. Adv Clin Chem 18: 1-101.

58. Ringsdorf WM Jr, Cheraskin E (1982) Vitamin C and human wound healing. Oral Surg Oral Med Oral Pathol 53: 231-236.

59. Goetzl EJ, Wasserman SI, Gigli I, Austen KF (1974) Enhancement of random migration and chemotactic response of human leukocytes by ascorbic acid. J Clin Invest 53: 813-818.

60. Siegel BV (1975) Enhancement of interferon production by poly ( $\mathrm{r} 1$ ), poly $(\mathrm{rC})$ in mouse cell cultures by ascorbic acid. Nature 254: 531-532.

61. Dahl H, Degre M (1976) The effect of ascorbic acid on production of human interferon and the antiviral activity in vitro. Acta Pathol Scand Sect B 84: 280-284.

62. McCormick WJ (1952) Ascorbic acid as a therapeutic agent. Arch Pediat 69:151-155.

63. Head KA (1998) Ascorbic Acid in the Prevention and Treatment of Cancer. Altern Med Rev 3: 174-196.

64. Wilson MK, Baguley BC, Wall C, Jameson MB, Findaly MP (2014) Review of high-dose intravenous vitamin $\mathrm{C}$ as an anticancer agent. AsiaPacific J Clin Oncol 10: 22-37.

65. Hickey S, Roberts H (2013) Vitamin C and Cancer: Is There A Use For Oral Vitamin C? JOM 28: 33-44.

66. Murata A, Morishige F, Yamaguchi H (1982) Prolongation of survival times of terminal cancer patients by administration of large doses of ascorbate. Int J Vit Nutr Res 23: 101-113.

67. Morishige F, Murata A (1979) Prolongation of survival times in terminal human cancer by administration of supplemental ascorbate. J Int Acad Prev Med 5: 47-52.

68. Hoffer A, Pauling L (1990) Hardin Jones biostatistical analysis of mortality data for cohorts of cancer patients with a large fraction surviving at the termination of the study and a comparison of survival times of cancer patients is receiving large regular oral doses of vitamin C and other nutrients with similar patients not receiving those doses. J Orthomol Med 5: 143-154.

69. Hoffer A, Pauling L (1993) Hardin Jones biostatistical analysis of mortality data for a second set of cohorts of cancer patients with a large fraction surviving at the termination of the study and a comparison of survival times of cancer patients receiving large regular oral doses of vitamin $\mathrm{C}$ and other nutrients with similar patients not receiving these doses. J Orthomol Med 8: 157-167.
70. Cameron E, Campbell A (1991) Innovation vs. Quality-Control - an Unpublishable Clinical-Trial of Supplemental Ascorbate in Incurable Cancer. Med Hypotheses 36: 185-189.

71. Jackson JA, Riordan HD, Bramhall NL, Neathery S (2002) Sixteen-Year History with High Dose Intravenous Vitamin C Treatment for Various Types of Cancer and Other Diseases. JOM 17: 117-119.

72. Carr AC, Vissers MCM, Cook JS (2014) The effect of intravenous vitamin $\mathrm{C}$ on cancer- and chemotherapy-related fatigue and quality of life. Front Oncol 4: 1-7.

73. Padayatty SJ, Riordan HD, Hewitt SM, Katz A, Hoffer LJ, et al. (2006) Intravenously administered vitamin $\mathrm{C}$ as cancer therapy: three cases. CMAJ 174: 937-942.

74. Hoffer LJ, Robitaille L, Zakarian R, Melnychuk D, Kavan P, et al. (2015) High-dose intravenous vitamin C combined with cytotoxic chemotherapy in patients with advanced cancer: a phase I-II clinical trial. PLoS One 10: e0120228.

75. Stephenson CM, Levin RD, Spector T, Lis CT (2013) Phase I clinical trial to evaluate the safety, tolerability, and pharmacokinetics of high-dose intravenous ascorbic acid in patients with advanced cancer. Cancer Chemother Pharmacol 72: 139-146.

76. Lee WJ (2009) The Prospects of Vitamin C in Cancer Therapy. Immune Network.

77. Maggini S, Wenzlaff S, Hornig D (2010) Essential role of vitamin C and zinc in child immunity and health. J Int Med Res 38: 386-414.

78. Pavlovic V (2010) A short overview of vitamin C and selected cells of the immune system. Cent Eur J Med 8: 1-10.

79. Strohle A, Wolters M, Hahn A (2011) Micronutrients at the interface between inflammation and infection-ascorbic acid and calciferol: part 1, general overview with a focus on ascorbic acid. Inflamm Allergy Drug Targets 10: 54-63.

80. Cameron E, Pauling L, Leibovitz B (1979) Ascorbic Acid and Cancer: A Review. Cancer Res 39: 663-681.

81. Gonzalez MJ, Miranda-Massari JR (2014) Anticancer Mechanisms of Vitamin C. In: Gonzalez MJ, Miranda-Massari JR Eds. New Insights on Vitamin C and Cancer. SpringerBriefs in Cancer Research.

82. Schleich T, Rodemeister S, Venturelli S, Sinnberg T, Garbe C, et al. (2013) Decreased plasma ascorbate levels in stage IV melanoma patients. Metab Nutr Oncol.

83. http://www4.dr-rath-foundation.org/pdf-files/cancerresearch.pdf

84. Venturelli S, Sinnberg TW, Berger A, Noor S, Levesque MP, et al. (2014) Epigenetic impacts of ascorbate on human metastatic melanoma cells. Front Oncol 4: 227.

85. Gao Y, Han Z, Li Q, Wu Y, Shi X, et al. (2015) Vitamin C induces a pluripotent state in mouse embryonic stem cells by modulating microRNA expression. FEBS J 282: 685-699.

86. Reczek CR, Chandel NS (2015) Revisiting vitamin C and cancer. Science 350: 1317-1318.

87. Yun J, Mullarky E, Lu C, Bosch KN, Kavalier A, et al. (2015) Vitamin C selectively kills KRAS and BRAF mutant colorectal cancer cells by targeting GAPDH. Science 350: 1391-1396.

88. http://www.doctoryourself.com/vitciv.html

89. Duconge J, Miranda-Massari JR, Gonzalez MJ, Jackson JA, Warnock W, et al. (2008) Pharmacokinetics of vitamin C: insights into the oral and intravenous administration of ascorbate. P R Health Sci J 27: 7-19.

90. Hickey DS, Roberts HJ, Cathcart RF (2005) Dynamic Flow: A New Model for Ascorbate JOM 20: 237-244.

91. Hickey S, Roberts H (2013) Vitamin C and Cancer: Is There A Use For Oral Vitamin C? JOM 28: 33-44.

92. Carreau A, El Hafny-Rahbi B, Matejuk A, Grillon C, Kieda C (2011) Why is the partial oxygen pressure of human tissues a crucial parameter? Small molecules and hypoxia. J Cell Mol Med 15: 1239-1253.

93. Malo C, Wilson JX (2000) Glucose Modulates Vitamin C Transport in Adult Human Small Intestinal Brush Border Membrane Vesicles. J Nutr 130: 63-69. 
Citation: Mastrangelo D, Massai L, Fioritoni G, Lo Coco F, Nuti R (2016) The Cure from Nature: The Extraordinary Anticancer Properties of Ascorbate (Vitamin C). J Integr Oncol 5: 157. doi:10.4172/2329-6771.1000157

94. Washko P, Levine M (1992) Inhibition of ascorbic acid transport in human neutrophils by glucose. J Biol Chem 267: 23568-23574. 